\title{
Game Analysis of New Rural Financial Institutions and Traditional Rural Financial Institutions Based on the Perspective of Fairness Mechanism
}

\author{
Jian Li \\ School of Economics \& Management, Northwest University, Xi'an, China, School of Economics \& \\ Management, Xi'an University, Xi'an, China
}

Keywords: New rural financial institutions, Traditional rural financial institutions, Fairness mechanism

\begin{abstract}
New rural financial institutions play an important role in promoting rural economic development and improving rural financial services, and become an important force in rural financial supply. Although there are conflicts of interests between new rural financial institutions and traditional rural financial institutions in terms of customer resources and business operation, there are broad space for cooperation in the fields of capital, information and technology. Our study introduces a kind of effective fair mechanism, through the establishment of a new type of rural financial institutions and the traditional cooperative game model of rural financial institutions, explore the strategy choice between both sides, and from the decrease of the cost of cooperation, create a revenue increment, coordinate earnings ratio in different Angle is put forward, such as promote long-term and stable cooperation strategy recommendations.
\end{abstract}

\section{Introduction}

New rural financial institutions play an important role in promoting rural economic development and upgrading rural financial services, and become an important force in rural financial supply. Although there are conflicts of interest between the new rural financial institutions and traditional rural financial institutions in terms of customer resources and business operations, there is a broad space for cooperation in the fields of capital, information and technology. Rural financial products have certain characteristics of public goods. Therefore, in the game of rural financial institutions, the behavior of participants has a strong positive externality. Since the contribution of rural financial institutions will also bring lower returns, such behavior will lead to the mutiny of all participants, which is a "social dilemma of public goods." Our research introduces an effective fairness mechanism. By establishing a cooperative game model between new rural financial institutions and traditional rural financial institutions, we explore strategic choices between the two parties, and reduce cooperation costs, create revenue increments, and coordinate the proportion of revenue. And other different angles put forward strategic proposals to promote long-term stable cooperation between the two sides.

Rural finance is the central link of the modern rural economy. It is an important force for comprehensively deepening rural reforms and accelerating agricultural modernization. It is a strong support under the new normal of "stable growth, structural adjustment, reform, and benefit for the people". At present, rural finance is still a weak node of China's entire financial system. Rural financial markets have problems such as insufficient financial supply and lagging financial service concepts, which have seriously affected the sustainable development of rural economy. China has adopted the "stock-based" reform model, and through the development of new rural financial institutions such as village banks and small loan companies, to some extent, it has solved the problems of imbalanced rural financial development and prominent contradiction between supply and demand. According to the latest data of the Banking Regulatory Commission, as of July 2017, 1,563 new rural financial institutions have been established nationwide, including 1,502 rural banks, 13 loan companies, and 48 rural mutual funds. Generally speaking, the new rural financial institutions have become the financial force for serving the "Issues of agriculture, farmer and rural 
area" and small and micro enterprises. Although the development of new rural financial institutions is rapid, due to the externality of capital, the profit-seeking nature of enterprises and the high risk of rural loans, the new rural financial institutions inevitably have a tendency of target shift in the development process. Traditional rural financial institutions represented by the Agricultural Bank of China and rural credit cooperatives have also failed to play their role in serving the "Issues of agriculture, farmer and rural area" issues. On the one hand, the withdrawal of commercial banking outlets from rural areas has led to a lack of comprehensive rural financial services; on the other hand, rural credit cooperatives have gradually become market-oriented under the market economic system, and the strength of serving "agriculture, rural areas and farmers" is obviously insufficient; Due to limited customer resources, the phenomenon of competition between the new rural financial institutions and traditional rural financial institutions has affected the development of "agriculture, rural areas and farmers" and small and micro enterprises. However, the new rural financial institutions and traditional rural financial institutions also have their own irreplaceable advantages. How to realize the complementary advantages of the new rural financial institutions and traditional rural financial institutions and achieve mutual benefit and win-win situation is an important problem in the current development of rural finance.

\section{Business Relationship and Game Process}

\subsection{Business relationship analysis}

New rural financial institutions and traditional rural financial institutions serve farmers or rural small and micro enterprises, using monetary credit as their main business, realizing the social value of rural financial institutions through financial supply and financial services, and at the same time obtaining profits to achieve sustainable management. However, the two sides also have the relationship of mutually beneficial cooperation and horizontal competition. New rural financial institutions and traditional rural financial institutions provide financial services to local farmers and enterprises in specific rural areas. Since the customer resources in a specific area are limited, there must be competition. Competition issues in customer resources. At the same time, the two sides also have the possibility of cooperation. The new rural financial institutions are basically the same as the traditional rural financial institutions in terms of customer positioning and product business, but there are differences in operating modes, risk protection, business processes and social image. Therefore, how to learn from each other's strengths and mutual benefits is a problem that both sides need to consider and solve. Compared with traditional rural financial institutions, new rural financial institutions have comparative advantages in terms of information, geography and business costs. Traditional rural financial institutions have rich experience in serving "agriculture, rural areas and farmers" , have high visibility and credibility in rural areas, and have a long-term customer base. The cooperation between the two sides can achieve complementary advantages and achieve a win-win situation. New financial institutions can rely on the good reputation, capital, and technology support of traditional rural financial institutions to expand their influence. Traditional rural financial institutions, through the establishment of business platforms with new financial institutions, and the use of their flexible operating mechanisms, high efficiency of decision-making, and information, channels and other help, to launch special products and services that can meet the rural financial market.

\subsection{Analysis of the game process}

It is assumed that the participants of the game, the new rural financial institutions and the traditional rural financial institutions are rational people and will make decisions to maximize their own interests under given conditions. There are two strategic choices for new rural financial institutions and traditional rural financial institutions: cooperation and competition. Cooperation means that the participants of the game have a positive attitude towards the expected benefits of the cooperation, and are willing to bear the risks brought by the cooperation, thus cutting the business 
with conflicts of interest, clarifying the division of business and business scope, and investing in product innovation. Competition means that the participants of the game hold a conservative attitude towards the expected return of the cooperation, that is, they cannot clarify the inputs and outputs of the cooperation, are unwilling to bear the risks brought by the cooperation, or have disputes over the expected distribution of the proceeds of the cooperation. Therefore, the existing business conditions are always maintained. Therefore, if the new rural financial institutions and traditional rural financial institutions choose a collaborative strategy, then the two sides will gain incremental synergy; if one of them chooses to cooperate and the other chooses competition, the partner will lose, and the competitor will produce Loss of cooperative credit and reputation; if both parties adopt a competitive strategy, they will each maintain normal returns. Therefore, cooperation with the players in the game means a trade-off between input and income.

In the context of public goods game (PGG), each player contributes an amount to a common pool. The total contribution will be multiplied by a factor and split evenly among all players. PGG is a impor- tant and widespread representation of group interactions [1], it plays an important role in a wide range of clusters, including the management of rural public goods $[2,3,4,5]$, the voluntary contribution of social public goods $[6,7,8,9]$, and the supply of international public goods $[10,11,12,13,14,15]$. It is necessary to study the stable supply of public goods.

Everyone chooses to cooperate is the phenomenon called collective rationality, where player's utility level must be higher than what this player gains when no one cooperates [16]. However, given the chara- cteristic attributes of public goods, a rational player will defect in the process of maximizing utility level. Consequently, the cooperators will die. In this situation, individual rationality conflicts with those of the cluster. PGG is called the "three social dilemmas" with Prison's dilemma and Tragedy of the Commons [17]. However, the cooperator is actually ubiquitous [18]. The vast majority of experiments $[19,20]$ show that individuals will invest about $50 \%$ of their initial endowments in one-off experiments, if the number of trials is not one, the final input is also not zero, obviously. Thus, market regulation must be continued, which is called intangible hand, apart from using a "tangible hand" to enable direct intervention [21,22].

\subsection{Analysis of the cooperative relationship under the fairness mechanism}

In this mechanism, cooperators can punish defectors by paying the cost, $C$, together. The

penalty paid individually by the defector is $\delta$. The new input of cooperator is $q_{c}^{\prime}=1+\frac{C}{n_{c}}$, and defector's is $q_{d}^{\prime}=\delta$. Of course, if no cooperator or defector exists, punishment does not exist. While punishment is implemented, we can determine that $0<n_{c}<n$. To simplify the formula, set

$$
g=(1-\delta) n_{c}+C .
$$

We analyze the average and variance of total input as follows:

$$
\begin{aligned}
& \mu^{\prime}=\frac{\left(1+\frac{C}{n_{c}}\right) n_{c}+\delta n_{d}}{n}=\frac{(1-\delta) n_{c}+C}{n}+\delta=\frac{g}{n}+\delta . \\
& \left(\sigma^{\prime}\right)^{2}=\frac{n_{c}\left(1+\frac{C}{n_{c}}-\frac{g}{n}-\delta\right)^{2}+n_{d}\left(\delta-\frac{g}{n}-\delta\right)^{2}}{n}=g^{2} \frac{n-n_{c}}{n^{2} n_{c}} .
\end{aligned}
$$

where $\mu^{\prime}$ and $\left(\sigma^{\prime}\right)^{2}$ are respectively the average and variance of total input when the cooperator punishes the defector. We analyze the fairness utilities of cooperator and defector based on (4).

$$
U_{e}=k_{2}(\mu-q-1) \sigma^{2} \text {. }
$$




$$
\begin{aligned}
& U_{c e}^{\prime}=k_{2}\left(\mu^{\prime}-q_{c}^{\prime}-1\right)\left(\sigma^{\prime}\right)^{2}=-k_{2} g^{3} \frac{\left(n-n_{c}\right)^{2}}{n^{3} n_{c}^{2}}-k_{2} g^{2} \frac{n-n_{c}}{n^{2} n_{c}} . \\
& U_{d e}^{\prime}=k_{2}\left(\mu^{\prime}-q_{d}^{\prime}-1\right)\left(\sigma^{\prime}\right)^{2}=k_{2} g^{3} \frac{n-n_{c}}{n^{3} n_{c}}-k_{2} g^{2} \frac{n-n_{c}}{n^{2} n_{c}} .
\end{aligned}
$$

Based on these equations, we can determine the total utilities of the cooperator and defector, respect- ively, as follows:

$$
\begin{aligned}
& U_{c}^{\prime}=\left[\frac{k_{1} n_{c}}{n}-\left(1+\frac{C}{n_{c}}\right)\right]-k_{2} g^{3} \frac{\left(n-n_{c}\right)^{2}}{n^{3} n_{c}^{2}}-k_{2} g^{2} \frac{n-n_{c}}{n^{2} n_{c}} . \\
& U_{d}^{\prime}=\left(\frac{k_{1} n_{c}}{n}-\delta\right)+k_{2} g^{3} \frac{n-n_{c}}{n^{3} n_{c}}-k_{2} g^{2} \frac{n-n_{c}}{n^{2} n_{c}} .
\end{aligned}
$$

The final decision of each player is the decision of the highest utility level. One's utility is decided by all variables. Thus, our paper forms this function, $F=U_{c}^{\prime}-U_{d}^{\prime}$, where $F$ is the simplification of $F\left(C ; \delta ; \delta ; n_{c} ; k_{1} ; k_{2}\right)$. Accordingly, we can determine a better strategy through the positive and negative of $F$.

$$
F=U_{c}^{\prime}-U_{d}^{\prime}=-\left(1-\delta+\frac{C}{n_{c}}\right)+k_{2}\left(\mu^{\prime}-q_{c}^{\prime}-1\right)\left(\sigma^{\prime}\right)^{2}-k_{2}\left(\mu^{\prime}-q_{d}^{\prime}-1\right)\left(\sigma^{\prime}\right)^{2}=-\frac{g}{n_{c}}-k_{2} \frac{g}{n_{c}}\left(\sigma^{\prime}\right)^{2} .
$$

We obtain that $F$ and $g$ have the opposite positive and negative values. There, $k_{1}$ and $k_{2}$ play a key role in solving the dilemma, but they can serve as an arbitrary value, which are determined by the attribu- tes of cluster and players. $n$ represents the scale of cluster, which will enlarge when utility of all players are positive, but, if there is a utility that is negative, the scale will shrink. In addition, $n_{c}$ will obviously change with the change in player's strategy. Thus, complex analysis is expected in this problem. At this time, $C$ and $\delta$ can be decided by authority. Their values should be taken within a reasonable range, which cannot stunt the development of cluster and should promote the emergence of cooperation. Relat- ively, let us first analyze $C$ and $\delta$ as follows:

Hence, it is obvious that

$$
\begin{aligned}
& \frac{\partial F}{\partial C}=-\frac{1}{n_{c}}-3 k_{2} g^{2} \frac{n-n_{c}}{n^{2} n_{c}^{2}}<0 . \\
& \frac{\partial F}{\partial \delta}=1+3 k_{2} g^{2} \frac{n-n_{c}}{n^{2} n_{c}}>0 .
\end{aligned}
$$

When other variables are constant, $F$ and $C$ are negatively related, and the correlation between $F$ and $\delta$ is positive. Thus, $F$ and $g$ are negatively related as well.

Based on this finding, we start to investigate $C$ and $\delta$ and define a new variable $A$.

If the values of $C$ and $\delta$ make $\frac{C}{n}+1 \geq \delta$, it must be $\frac{C}{n_{c}}+1 \geq \delta$. No mater what value $n_{c}$ takes, the input of cooperator $\left(q_{c}^{\prime}=1+\frac{C}{n_{c}}\right.$ ) must not be less than defector's ( $q_{d}^{\prime}=\delta$ ), which makes $g \geq 0$ and $F \leq 0$. Therefore, the total utility level of the cooperator cannot be higher whether or not punishment is impleme- nted. Such phenomenon is a social dilemma. This result reveals that punitive cost is excessive, or the penalties are extremely low to form cooperation. Thus, their values are unreasonable, it should be $\frac{C}{n}+1-\delta=\frac{C+n(1-\delta)}{n}<0$. Also, we could know $1-\delta<0$, if not, this inequation cannot be logical.

We can obtain $C+n(1-\delta)<0<C+0(1-\delta)$ by combining the nature of $C$ and $\delta$. Then, we can 
determine the existence of $A$, whose range is 0 to $n$, to make $C+A(1-\delta)=0$. We can also say that $A=\frac{C}{\delta-1}$

\section{Suggestions}

New rural financial institutions and traditional rural financial institutions should base their cooperation on different organizational characteristics and comparative advantages to reduce the cooperation costs of both parties. In this regard, the new rural financial institutions should give full play to the regional advantages of local financial institutions and the information advantages close to farmers, focusing on providing targeted financial services for farmers and rural small and micro enterprises. Optimize the guarantee method and repayment method, and gradually establish and improve the regular credit risk assessment system and the credit cycle incentive system. Traditional rural financial institutions should provide large-scale, industrial chain financial services for middleand high-end rural customers, and support rural characteristic industries in the form of packaged loans and joint loans.

The new rural financial institutions should cooperate with traditional rural financial institutions based on agricultural banks to develop financial products and services that can meet the reasonable needs of local customers, and jointly promote standardized insurance, wealth management, guarantees and other products and services. In response to the characteristics of the rural credit market, the participants in the industrial chain, commodity circulation and service provision were deeply explored, and the mutual funds, logistics and information were used to explore market opportunities, and a financial product suitable for the rural market was set up.

New rural financial institutions and traditional rural financial institutions will face the credit risks of rural customer groups and the systemic risks of agricultural industries. Therefore, it is necessary to strengthen the cooperation. Management of operational risks, credit risks and legal risks, and the proportion of cooperation revenues recognized based on the risks assumed during the cooperation process.

\section{References}

[1] M. Perc, J. Gómez-Gardeñes, A. Szolnoki, L. M. Floría, Y. Moreno, Evolutionary dynamics of group interactions on structured populations: a review, Journal of the royal society interface, 10(80) (2013) 20120997.

[2] A. Hopfensitz, J. Miquelflorensa, Mill ownership and farmer's cooperative behavior: the case of Costa Rica coffee farmers, Journal of Institutional Economics, 13(3) (2017) 623-648.

[3] T. Reeves, H. Ohtsuki, S. Fukui, Asymmetric public goods game cooperation through pest control, Journal of Theoretical Biology, 435 (2017) 238-247.

[4] S. L. Gomes, L. M. Hermans, W. A. H. Thissen, Extending community operational research to address institutional aspects of societal problems: Experiences from peri-urban Bangladesh, European Journal of Operational Research, 268(3) (2018) 904-917.

[5] M. Muller, J. Rommel, C. Kimmich, Farmers' Adoption of Irrigation Technologies: Experimental Evidence from a Coordination Game with Positive Network Externalities in India, German Economic Review, 19(2) (2018) 119-139.

[6] P. Liu, J. Liu, Contribution diversity and incremental learning promote cooperation in public goods games, Physica A-Statistical Mechanics and Its Applications, 486 (2017) 827-838.

[7] J. Ning, V. Babich, R\&D Investments in the Presence of Knowledge Spillover and Debt Financing: Can Risk Shifting Cure Free Riding? M\&Som-Manufacturing\&Service Operations Management, 20(1) (2018) 97-112. 
[8] W. Que, Y. B. Zhang, S. B. Liu, The spatial spillover effect of fiscal decentralization on local public provision: Mathematical application and empirical estimation, Applied Mathematics and Computation, 331 (2018) 416-429.

[9] S. Wang, Z. J. Xu, L. Z. Zhang, Non-Fixed Investment in Voluntary Public Goods Games, Journal of Korean Physical Society, 72(9) (2018) 972-979.

[10] A. Tavoni, A. Dannenberg, G. Kallis, A. Löschel, Inequality, communication, and the avoidance of disastrous climate change in a public goods game, Proceedings of the National Academy of Sciences, 108(29) (2011) 11825-11829.

[11] S. Barrett, Coordination vs. voluntarism and enforcement in sustaining international environmental cooperation, Proceedings of the National Academy of Sciences of the United States of America, 113(51) (2016) 14515-14522.

[12] E. M. Hafner-Burton, S. Haggard, D. A. Lake, D. G. Victor, The Behavioral Revolution and International Relations, International Organization, 71(suppl 1) (2017) S1-S31.

[13] L. Helland, J. Hovi, H. Saelen, Climate leadership by conditional commitments, Oxford Economic Papers-New Series, 70(2) (2018) 417-442.

[14] G. Schwerhoff, U. Kornek, K. Lessmann, M. Pahle, Leadership in Climate Change Mitigation: Consequences and Incentives, Journal of Economic Surveys, 32(2) (2018) 491-517.

[15] S. Vesely, C. A. Klockner, Global Social Norms and Environmental Behavior, Environment and Behavior, 50(3) (2018) 247-272.

[16] T. Wu, L. Wang, Adaptive play stabilizes cooperation in continuous public goods games, Physica A-Statistical Mechanics and Its Applications, 495 (2018) 427-435.

[17] G. Hardin,. TRAGEDY OF COMMONS. Science. 162(3859) (1968) 1243-1248.

[18] S. Bowles, H. Gintis, A Cooperative Species:Human Reciprocity and Its Evolution, Economics Books, 50(3) (2011) 797-803.

[19] Ledyard, O. John, Public Goods: A Survey of Experimental Research, Handbook of Experimental Economics Results, 1 (9405003) (1997).

[20] M. Archetti, I. Scheuring, Coexistence of cooperation and defection in public goods games, Evolution, 65(4) (2011) 1140-1148.

[21] C. Reif, D. Rübbelke, A. Löschel, Improving voluntary public good provision through a nongovernmental, endogenous matching mechanism: experimental evidence, Environmental and Resource Economics, 67(3) (2017) 559-589.

[22] A. Leibbrandt, J. Lynham, Does the paradox of plenty exist? Experimental evidence on the curse of resource abundance, Experimental Economics, 21(2) (2018) 337-354. 